\title{
MONITOREO DE HONGOS AMBIENTALES EN LABORATORIOS Y RESERVAS PATRIMONIALES BIOARQUEOLÓGICAS
}

\author{
(Monitoring of environmental fungi in laboratories and \\ bioarqueological patrimonial reserves)
}

Cepeda, Romina ${ }^{1}$; Luque, Lizet $^{2}$; Ramirez, Darío ${ }^{3}$; Franco, Paola ${ }^{4}$; Fabra, Mariana ${ }^{3 *}$

\begin{abstract}
${ }^{1}$ Servicio de Microbiología, Laboratorio Ace de análisis clínicos y especializados. Córdoba, Argentina. ${ }^{2}$ Laboratorio de Microbiología, Servicio de Micología, Clínica Universitaria Reina Fabiola. Córdoba, Argentina. ${ }^{3}$ Instituto de Antropología de Córdoba (IDACOR)- Consejo Nacional de Investigaciones Científicas y Técnicas (CONICET), Museo de Antropología (Facultad de Filosofía y Humanidades, Universidad Nacional de Córdoba) Córdoba, Argentina. ${ }^{4}$ Museo en Ciencias de la Salud, Hospital Nacional de Clínicas, Universidad Nacional de Córdoba, Argentina. *Autor para correspondencia: marianafabra@gmail.com

RECIBIDO: 11 de Septiembre de 2019 APROBADO: 01 de Octubre de 2019
\end{abstract}

DOI: 10.22370/bolmicol.2019.34.2.1909

LOS AUTORES DECLARAN NO TENER CONFLICTO DE INTERESES

Palabras claves: Cladosporium sp., Aspergillus sp., Penicillium sp., Chrysonilia sp., Rhodotorula sp., bioseguridad.

Key words: Cladosporium sp., Aspergillus sp., Penicillium sp., Chrysonilia sp., Rhodotorula sp.; biosafety.

\section{RESUMEN}

Los hongos son organismos cosmopolitas que pueden desarrollarse en los sustratos más variados, en diversos climas e incluso en condiciones extremas. Contribuyen al deterioro de infraestructuras y colecciones arqueológicas, producen toxinas y sustancias volátiles que en ocasiones causan enfermedades respiratorias, sistémicas y alergias. El objetivo del presente trabajo es monitorear la presencia de hongos en laboratorios de Bioarqueología y Biología Molecular, y generar un protocolo de buenas prácticas de limpieza sobre estos ambientes. Se trata de cuatro laboratorios ubicados en el Instituto de Antropología de Córdoba, en el Área de Arqueología de la Dirección de Patrimonio Cul- 
tural de la Agencia Córdoba Cultura S.E. y en la Reserva Patrimonial del Museo de Antropología. Se aplicó metodología gravimétrica, disponiendo placas de Petri $(n=30)$ con medio de cultivo Agar Sabouraud glucosado con antibiótico, en distintas superficies de los espacios mencionados, durante 5 minutos. Seguidamente, fueron incubadas en estufa durante una semana a $28^{\circ} \mathrm{C}$. La identificación de las distintas colonias se llevó a cabo mediante lupa y microscopía óptica, realizando recuento de las mismas e identificación a nivel género. Se detectó la presencia de Cladosporium sp., Aspergillus sp., Penicillium sp., Chrysonilia sp. y Rhodotorula $\mathrm{sp}$. Algunos de los géneros identificados pueden provocar distintas patologías respiratorias. Se presentan los resultados, discriminando por laboratorios, así como la propuesta de buenas prácticas y de limpieza generadas para estos ambientes, y las normas de bioseguridad e higiene que garanticen una reducción en la concentración ambiental de la microbiota fúngica a la cual están expuestos los trabajadores, minimizando así los riesgos de exposición a enfermedades y daños en las colecciones bioarqueológicas.

\section{ABSTRACT}

Fungi are cosmopolitan organisms that can develop in most varied substrates, in different climates and even in extreme conditions. They contribute with deterioration of infrastructures and archaeological collections, produce toxins and volatile substances that sometimes cause respiratory systemic diseases and allergies. The aim of this paper is to monitor the presence of fungi in Bioarchaeology and Molecular Biology laboratories, and to generate a protocol of good cleaning practices on these environments. These are four laboratories, located in the Institute of Anthropology of Córdoba, Archeology Department of the Cultural Heritage Management of the Cordoba Culture Agency S.E and the Patrimonial Reserve of the Museum of Anthropology. A non-volumetric methodology was applied, with Petri dishes $(\mathrm{n}=30)$ being prepared with Sabouraud Agar medium with antibiotic, on different surfaces of the mentioned spaces, for 5 minutes. Then, they were incubated in an oven for one week at $28^{\circ} \mathrm{C}$. The identification of the different colonies was carried out by using magnifying glass and optical microscopy, counting them and identifying them at the genus level. The presence of Cladosporium sp., Aspergillus sp., Penicillium sp., Chrysoinilia sp., Rhodotorula sp. were detected. Some of the identified genera can cause different respiratory pathologies. The results are presented, discriminated by laboratories, and a proposal of good practices protocol and cleaning generated for these environments, as well as biosafety and hygiene standards that guarantee a decrease in fungal microbiota environmental concentrations that reduce not only the risks of exposure to diseases for workers, but also damages in the bioarchaeological collections.

\section{INTRODUCCION}

Los hongos son organismos cosmopolitas que pueden desarrollarse en los sustratos más variados, en todos los climas de la tierra e incluso en condiciones extremas. Su nicho ecológico es tan amplio, que sus esporas incluso sobrepasan la atmósfera (Aira et al. 2003). El desarrollo fúngico está supeditado a ciertas condiciones ambientales tales como la humedad relativa, temperatura, precipitación, inversiones térmicas, contaminación, disponibilidad de sustrato y actividades humanas, las que influyen de manera determinante en la proliferación y propagación de las partículas fúngicas hacia los espacios interiores (Guerrero et al. 2003). Elementos como alimentos, plantas, flores, polvo, textiles, cortinas, alfombras, mobiliario en mal estado, sobre todo de madera, promueven la contaminación biológica del aire (Albright 2001). La humedad en los espacios interiores, ya sea en el aire o en paredes y techos, es un factor que promueve la germinación de esporas y el albergue de hongos como Penicillium y Aspergillus. Además de contribuir al deterioro de infraestructuras 
y materiales, son agentes etiológicos productores de toxinas y propágulos, que en ocasiones causan enfermedades respiratorias, sistémicas y alergias. (Daza Perez et al. 2015)

Las esporas fúngicas son componentes normales de ambientes externos y pueden ser la fuente contaminante de los ambientes internos, y muchos de estos pueden servir como sitios de amplificación para el crecimiento de los hongos (Bueno et al. 2003). La inhalación sistémica de esporas y fragmentos de micelio de hongos puede inducir una afección alérgica respiratoria, tanto en las vías aéreas superiores como en las inferiores. Los componentes alergénicos de hongos contienen moléculas, como glucoproteínas, proteínas y polisacáridos, que pueden desencadenar reacciones de hipersensibilidad tipo I (Ruiz Gonzalez et al., 2016).

El Centro para Prevención y Control de Enfermedades (CDC) en su documento relativo al control ambiental recomiendan la utilización de cinco criterios bien definidos para relacionar una fuente ambiental con la transmisión de microorganismos que causan infección, entre ellos, a) Presencia de un número adecuado de microorganismos patógenos (dosis), b) Microorganismos con suficiente virulencia, c) Presencia de un huésped susceptible, d) Un modo eficiente de transmisión del microorganismo desde la fuente de infección hasta el huésped susceptible y e) Presencia de una puerta de entrada adecuada en el huésped (Sheulster et al.,2004). Cabe destacar que la sola presencia de microorganismos en el cultivo de una superficie u objeto inanimado no es suficiente, a menos que se trate de un patógeno primario como Histoplasma capsulatum, Coccidioides spp, Paracoccidioides spp, Blastomyces dermatitidis o Penicillium marneffei.

Los problemas de conservación que afrontan las colecciones bioantropológicas se deben principalmente a que los ejemplares están compuestos por sustancias proteicas, que componen los huesos, pelos y la piel así como de materiales celulósicos en sus elementos accesorios; sustratos potenciales para el desarrollo de agentes de biodeterioro como los hongos (Nitiu et al., 2010). Si bien en los últimos años se han realizado estudios para evaluar la patogenicidad y potencial biodeteriorante de ciertos géneros de hongos en instituciones patrimoniales (Sterflinger 2010; Borrego et al. 2010, 2012; Bueno et al. 2003; Molina y Borrego 2014, 2016; Herrera et al. 2015; Nitiu et al. 2015), no es frecuente su estudio en ámbitos vinculados tanto a reservas patrimoniales que contienen materiales bioarqueológicos, o laboratorios donde se realizan estudios bioantropológicos (Lopez-Martinez et al.2007; Rojo Pérez 1998). En este contexto, el objetivo de este trabajo es evaluar la calidad del aire revelando la presencia o ausencia de hongos ambientales en laboratorios y áreas de reserva patrimonial dependientes del Instituto de Antropología de Córdoba, Consejo Nacional de Investigaciones Científicas y Técnicas-en adelante, IDACOR-, del Museo de Antropología, Facultad de Filosofía y Humanidades, Universidad Nacional de Córdoba -en adelante RPMA- y del Centro de Investigaciones del Patrimonio Arqueológico de Córdoba (CIPAC), del Gobierno de la Provincia de Córdoba, Agencia Córdoba Cultura, -en adelante, CIPACcon el fin de analizar el impacto de estos agentes no sólo sobre los trabajadores sino también sobre las colecciones con las que allí se trabaja.

\section{MATERIALES Y MÉTODOS}

\section{Puntos de muestreo}

El estudio se realizó en el mes de Mayo de 2017 en dos laboratorios ubicados en el IDACOR (Bioarqueología/PostPCR -BIOARQ- y pre PCR -PCR-), uno en CIPAC -Laboratorio de Biorqueologia, BIOARQ CIPAC- y el área de resguardo de restos humanos, ubicado en la Reserva Patrimonial del Museo de Antropología -RPMA-, todos en la ciudad de Córdoba Capital, provincia de Córdoba, Argentina. En el caso de los laboratorios ubicados en el IDACOR en el laboratorio BIOARQ se realizan tareas vinculadas con análisis genéticos 
sobre material arqueológico y moderno, particularmente electroforesis en gel de agarosa y acrilamida, análisis microscópico de microrestos vegetales y paleoparasitológicos, resguardo de colecciones bioarqueológicas, y además tareas de oficina. Por otra parte, en el laboratorio PCR se realiza extracción de $\mathrm{ADN}$ moderno, $\mathrm{y}$ análisis por reacción en cadena de la polimerasa o PCR de ADN antiguo y moderno. En el caso de la Reserva Patrimonial, particularmente la "E", alberga más de 300 lotes conteniendo restos óseos humanos pertenecientes tanto a la colección histórica del Museo de Antropología, así como restos humanos recuperados mediante trabajos de arqueología de rescate. En el caso del laboratorio ubicado en dependencias del Centro de Investigaciones del Patrimonio Arqueológico de Córdoba (CIPAC), del Gobierno de la Provincia de Córdoba, Agencia Córdoba Cultura, se realizan tareas de análisis bioarqueológico así como también se conservan restos humanos de un total aproximado de 60 individuos, recuperados mediante tareas de rescate arqueológico realizadas en la provincia de Córdoba.

\section{Muestreo microbiológico del aire}

En primer lugar se llevó a cabo un análisis observacional de las condiciones de los laboratorios o reservas patrimoniales para determinar los espacios en los que se dispondrían las placas para la pesquisa de esporas fúngicas presentes en el ambiente. Basados en las dimensiones de los distintos laboratorios, el flujo de personal y las cercanías a corrientes de aire, se determinó el número de placas para cada zona (Sáchis 2000): 4 placas en BIOARQ y en PCR, 12 placas en BIOARQ CIPAC y 10 placas en RPMA.

Se empleó el método microbiológico pasivo siguiendo la técnica de la placa expuesta donde ocurre la sedimentación de las partículas del aire. Dicha técnica consiste en exponer al ambiente placas $(\mathrm{n}=30)$ de Petri de $90 \mathrm{~mm}$ de diámetro, que contenían Agar Sabouraud glucosado (Britania) con cloranfenicol, durante cinco minutos, en las distintas zonas. Este método se denomina no volumétrico ya que no se evalúa un volumen fijo de aire (Bueno et al. 2003) (Figura 1).

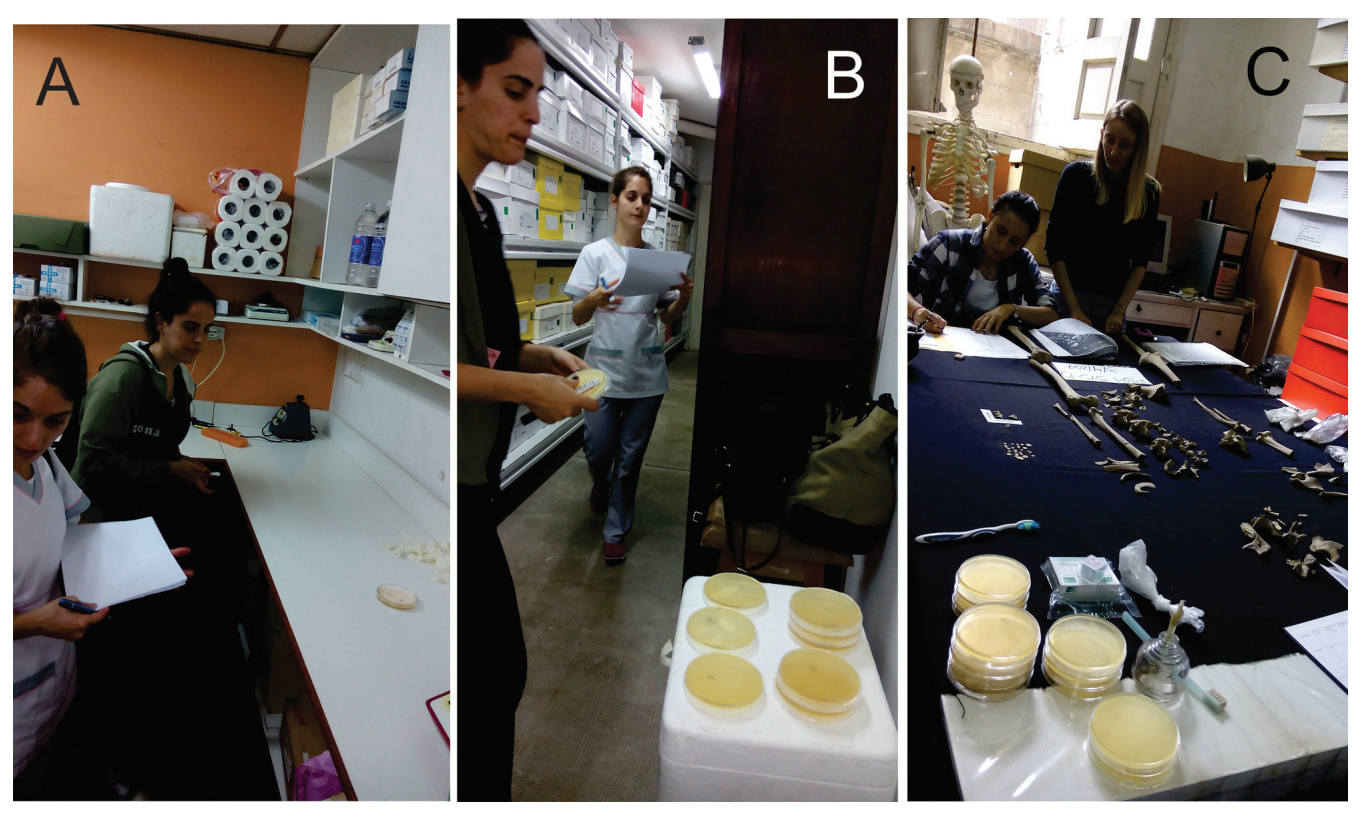

Figura 1. Colocación de placas de Petri en los espacios analizados: a) Laboratorio de PCR - PCR-, b) Reserva Patrimonial "E", Museo de Antropología -RPMA- y c) Laboratorio ubicado en dependencias del Centro de Investigaciones del Patrimonio Arqueológico de Córdoba (CIPAC), del Gobierno de la Provincia de Córdoba, Agencia Córdoba Cultura, -BIOARQ CIPAC-. 
En cuanto se recibieron las muestras en el Servicio de Microbiología se incubaron en estufa de cultivo a $28^{\circ} \mathrm{C}$, durante 7 días, temperatura óptima de crecimiento de la mayoría de los hongos ambientales oportunistas. Se realizaron lecturas diarias de las placas para detectar crecimiento lo antes posible, moviendo con cuidado las que presentaban crecimientos para evitar siembras secundarias y no alterar el recuento de colonias.

Paralelamente a la incubación de las muestras se llevó a cabo un control de calidad interno en el cual se controlaron las condiciones del aire del laboratorio y de las estufas de incubación. Se incubaron placas control con medio de cultivo para descartar posibles contaminantes provenientes del ambiente o de los medios utilizados.

Tras el período de incubación se realizó el recuento de las unidades formadoras de colonias (ufc) obtenidas en los diferentes espacios. Para determinar la concentración microbiana del aire, expresada en unidades formadoras de colonias por m3 de aire (ufc.m-3) según la ecuación descrita por Omeliansky:

$$
N=5 a \cdot 10^{4}(b \cdot t)^{-1}
$$

$\mathbf{N}=$ Concentración microbiana en ufc $\cdot \mathrm{m}^{-3}$

$\mathbf{a}=$ número de colonias por placa Petri, $\mathbf{b}=$ es la superficie de la placa $\left(\mathrm{r}^{2} \mathrm{x} \pi\right)$ expresada en $\mathrm{cm}^{2}$

$\mathbf{t}=$ tiempo de exposición en minutos.

Para determinar el grado de contaminación se compararon las concentraciones microbianas obtenidas con la escala propuesta por Omeliansky (Garcíaや2016).

Identificación y caracterización de los agentes aislados

La identificación se llevó a cabo siguiendo los métodos habituales (Bueno et al. 2003), aquellos hongos que no desarrollaron elementos de reproducción asexual fueron considerados de micelio estéril. En este caso se hizo una identificación presuntiva rápida, mediante la visualización del aspecto macroscópico de las colonias a la lupa (se describió el anverso y reverso de cada cepa según textura, color, diámetro de la colonia y la presencia de pigmentos difusibles al medio) y la observación microscópica con azul de lactofenol, de las estructuras de reproducción asexual (Barnett y Hunter 1997).

La metodología convencional, en la que se realiza la identificación de los hongos a través del análisis macroscópico y microscópico de las colonias, sólo nos permite hacer una identificación fenotípica de los agentes y determinar hasta nivel de género a los microorganismos encontrados. Esta metodología no permite identificar hongos filamentosos hialinos o dematiaceos de micelio estéril, ya que para ello deberían aplicarse técnicas de biología molecular (Bueno et al. 2003), lo mismo debería hacerse para identificar a nivel de especie, ya que las técnicas moleculares han revolucionado la taxonomía fúngica en los últimos años y se han descubierto nuevas especies filogenéticas, que comparten características macro y microscópicas.

\section{RESULTADOS}

En el caso de las placas ubicadas en el laboratorio de Bioarqueología y Post PCR -BIOARQse recuperó un total de 15 colonias, 10 sin fructificar, 4 de Cladosporium y 1 de Aspergillus. Los espacios más afectados fueron la mesada, la mesa de trabajo y el escritorio (Figura 2a).

En el caso del laboratorio de PCR -PCRfue donde menos colonias fúngicas se encontraron (9), 7 colonias de micelio estéril, 1 de Aspergillus y 1 de Chrysonilia. Los espacios más afectados fueron la pileta y la campana (Figura 2b). 

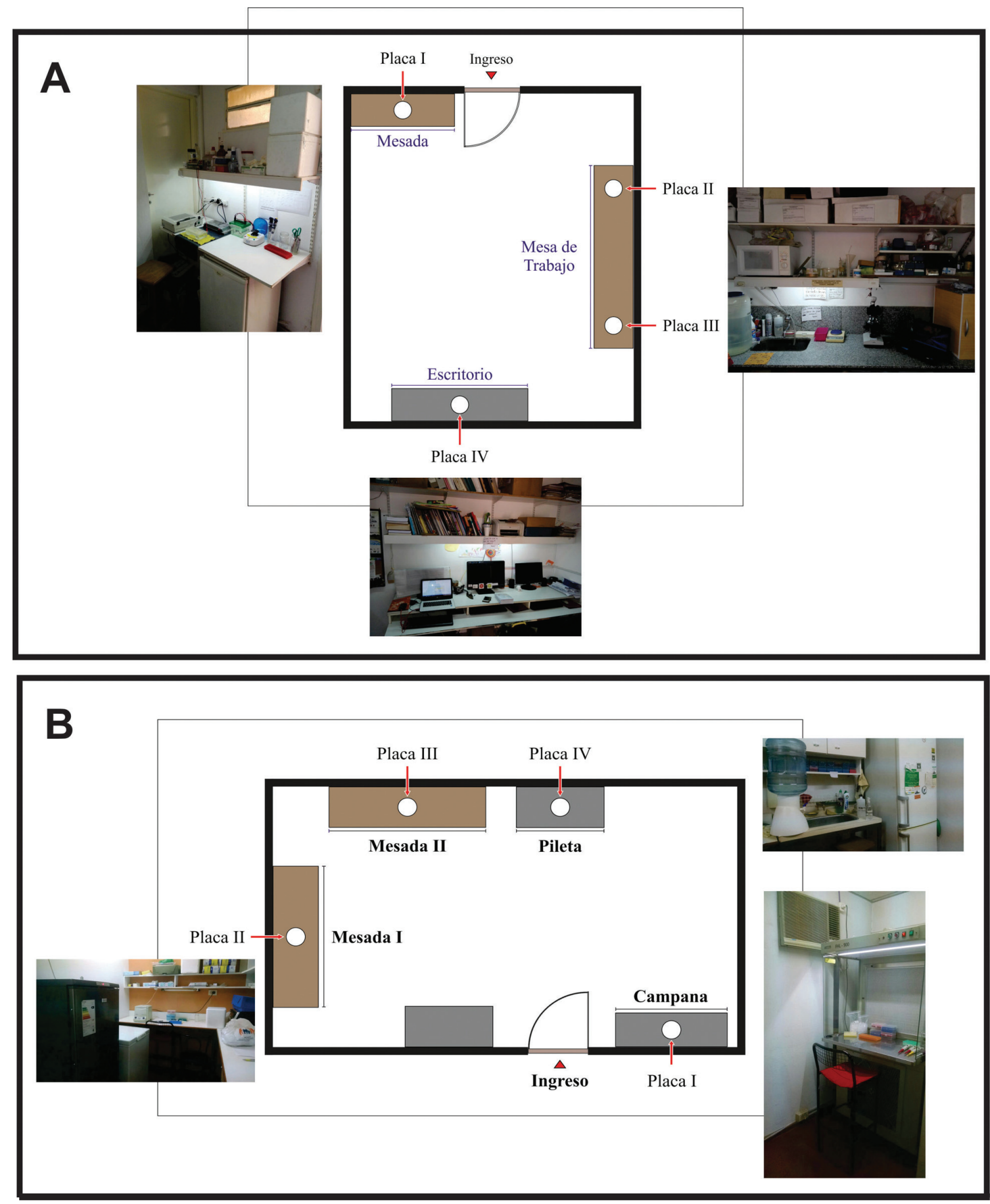

Figura 2. Croquis con la distribución de placas en los laboratorios ubicados en el Instituto de Antropología de Córdoba: A) BIOARQ, B) PCR.

En el caso de la Reserva Patrimonial del Museo de Antropología, -RPMA-, se recuperaron un total de 11 colonias, 7 con micelio estéril y 4 de Cladosporium. Las áreas más afectadas fueron los estantes 1, 5, 6 y 7 (Figura 3).
Finalmente, el área más afectada, no sólo por la cantidad sino también por variedad de géneros, fue el laboratorio de análisis de restos humanos, ubicados en dependencias del CIPAC, -BIOARQ CIPAC- donde se recuperó un total de 


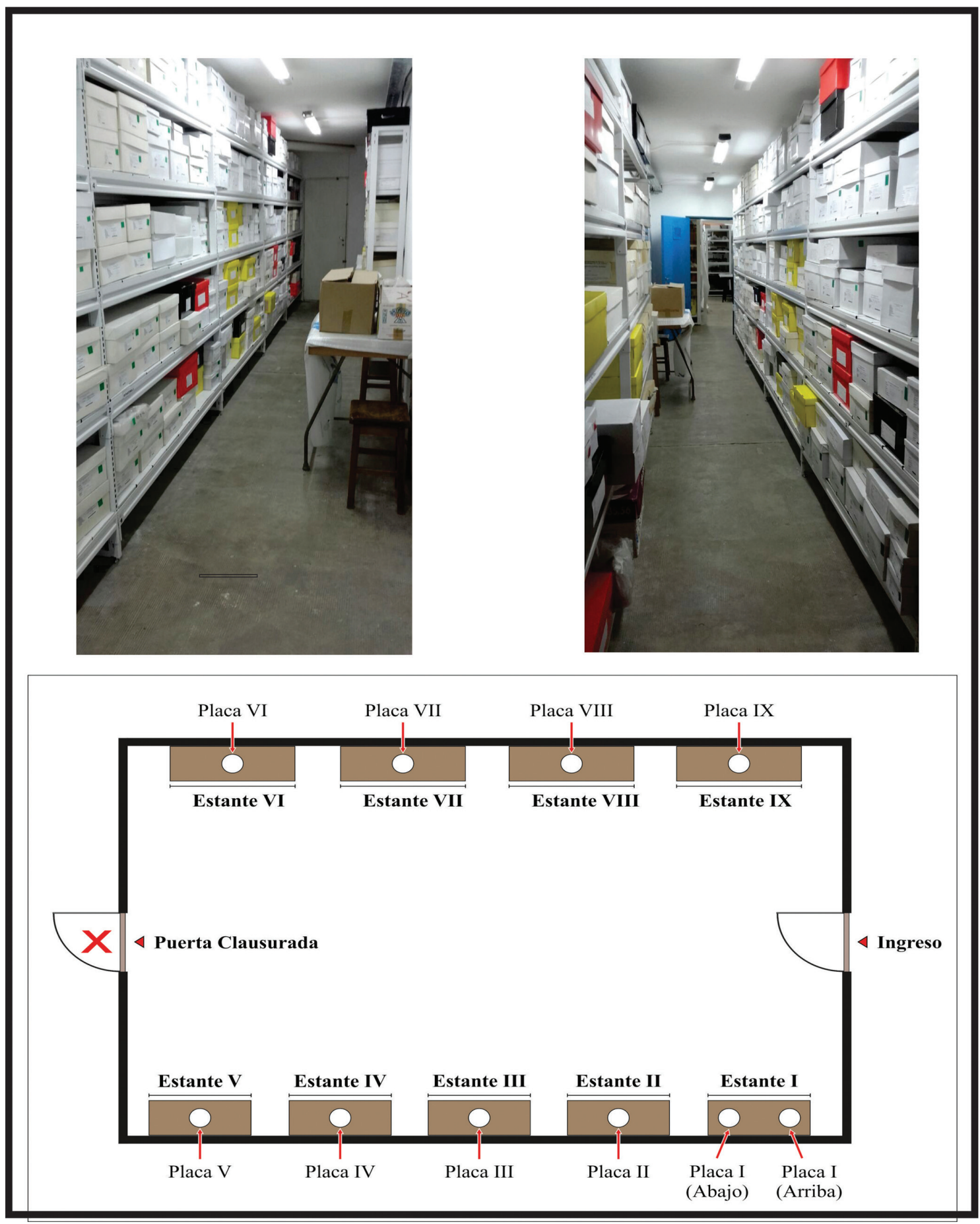

Figura 3. Croquis con la distribución de placas en la Reserva Patrimonial del Museo de Antropología -RPMA-.

61 colonias, 40 de micelio estéril, 8 de Cladosporium, 6 de Aspergillus, 4 de Penicillium, 2 de Chrysonilia y 1 de Rhodotorula, en todas las áreas muestreadas (Figura 4).
En total, se recuperaron 56 cepas, a partir de la exposición de 30 placas, pertenecientes a 4 géneros, levaduras y hongos clasificados como Mycelia sterilia (Tabla 1, Figura 5). 


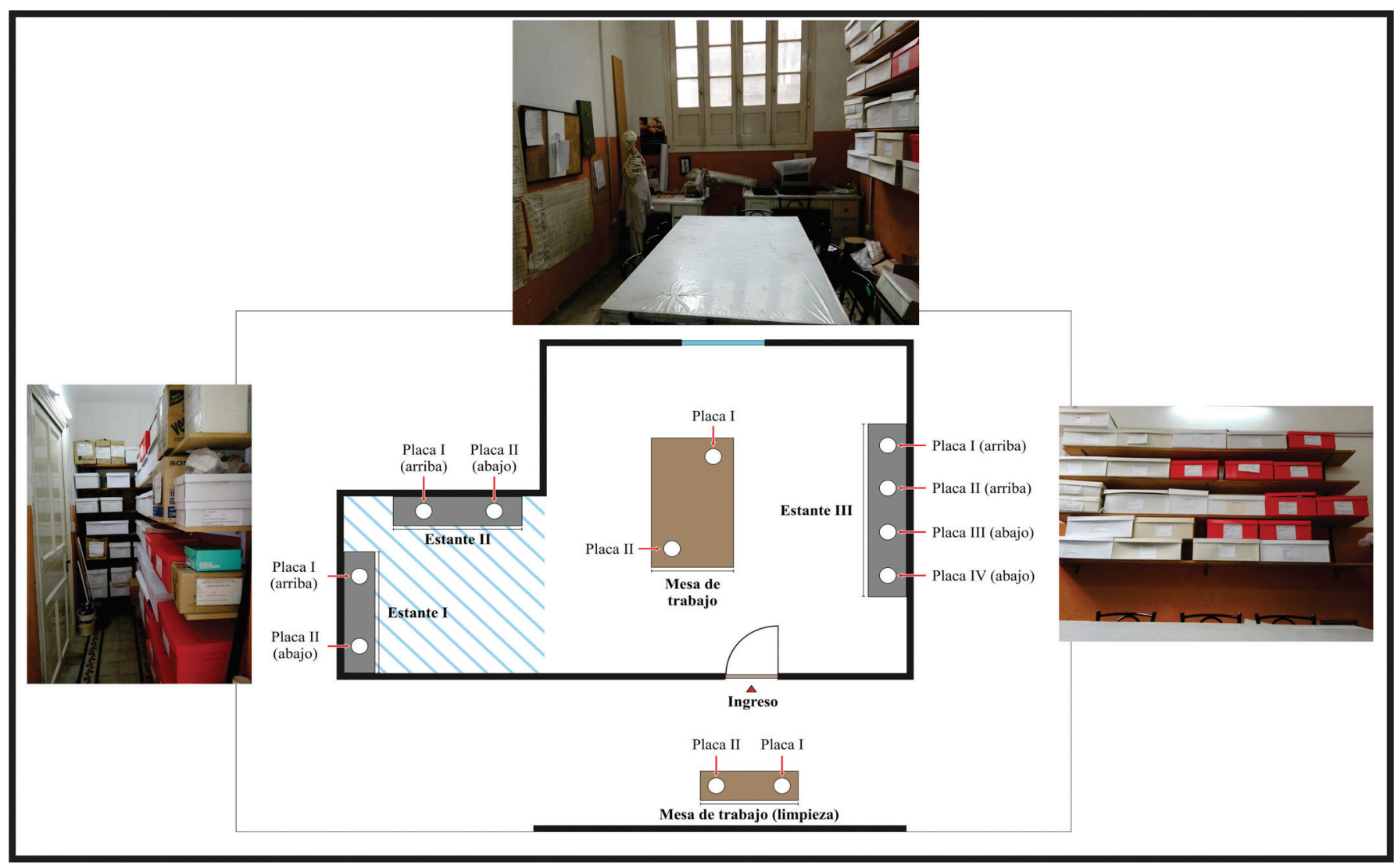

Figura 4. Croquis con la distribución de placas en el Laboratorio ubicado en dependencias del Centro de Investigaciones del Patrimonio Arqueológico de Córdoba (CIPAC), del Gobierno de la Provincia de Córdoba, Agencia Córdoba Cultura, -BIOARQ CIPAC-.

Tabla 1. Cantidad de colonias por género fúngico registrados en cada laboratorio y reserva patrimonial.

\begin{tabular}{lllll}
\hline Tipos morfológicos & BIOARQ & PCR & RPMA & BIOARQ CIPAC \\
\hline Cladosporium & $\mathbf{4}$ & - & $\mathbf{4}$ & $\mathbf{8}$ \\
Aspergillus & - & $\mathbf{1}$ & - & $\mathbf{6}$ \\
Penicillium & $\mathbf{1}$ & - & - & $\mathbf{4}$ \\
Chrysonilia & - & $\mathbf{1}$ & - & $\mathbf{2}$ \\
Rhodontorula & - & - & - & $\mathbf{1}$ \\
Hongos/Levaduras & & & & \\
Sin fructificar & $\mathbf{1 0}$ & $\mathbf{7}$ & $\mathbf{7}$ & $\mathbf{4 0}$ \\
\hline Total & 15 & 9 & 11 & 61 \\
\hline
\end{tabular}


Monitoreo de hongos ambientales en laboratorios y reservas patrimoniales bioarqueológicas - Cepeda R. et al

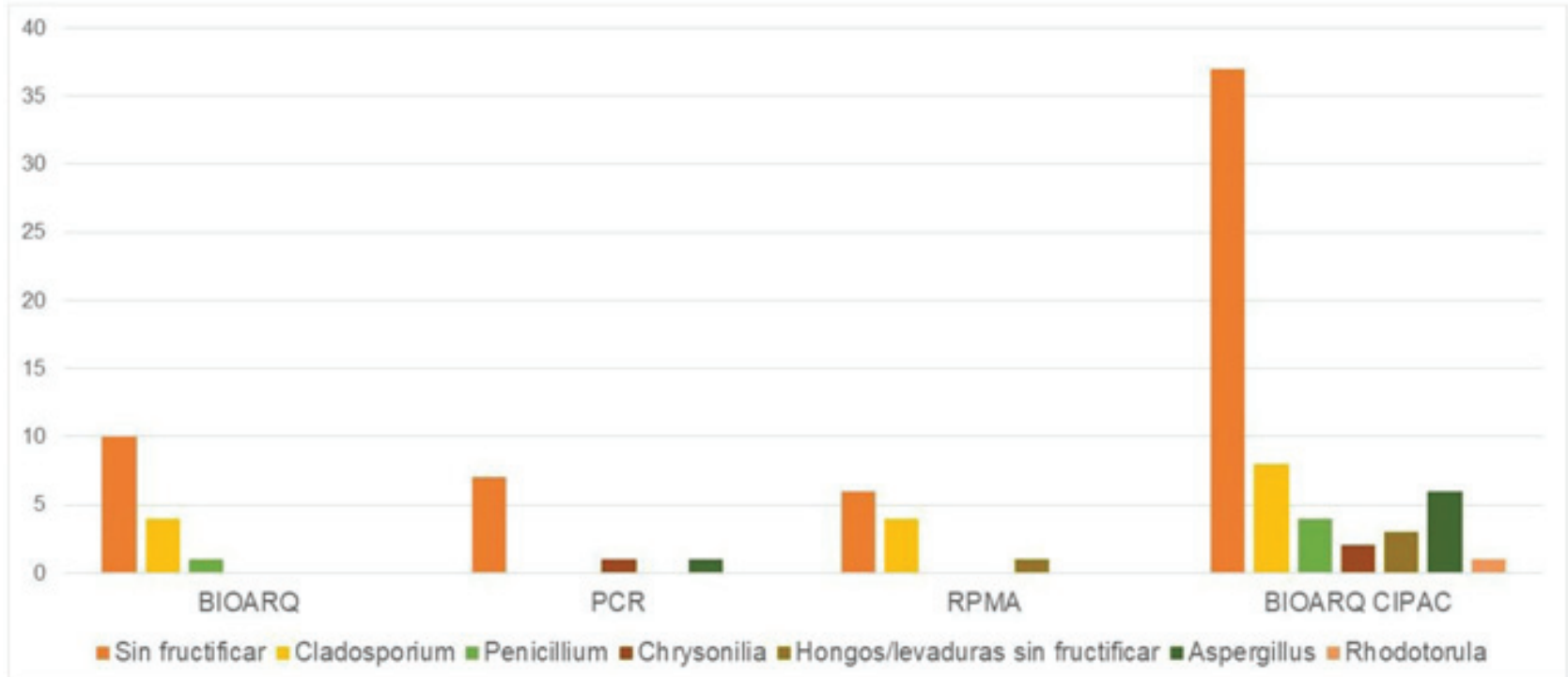

Figura 5. Cantidad de colonias por géneros recuperadas en cada área.

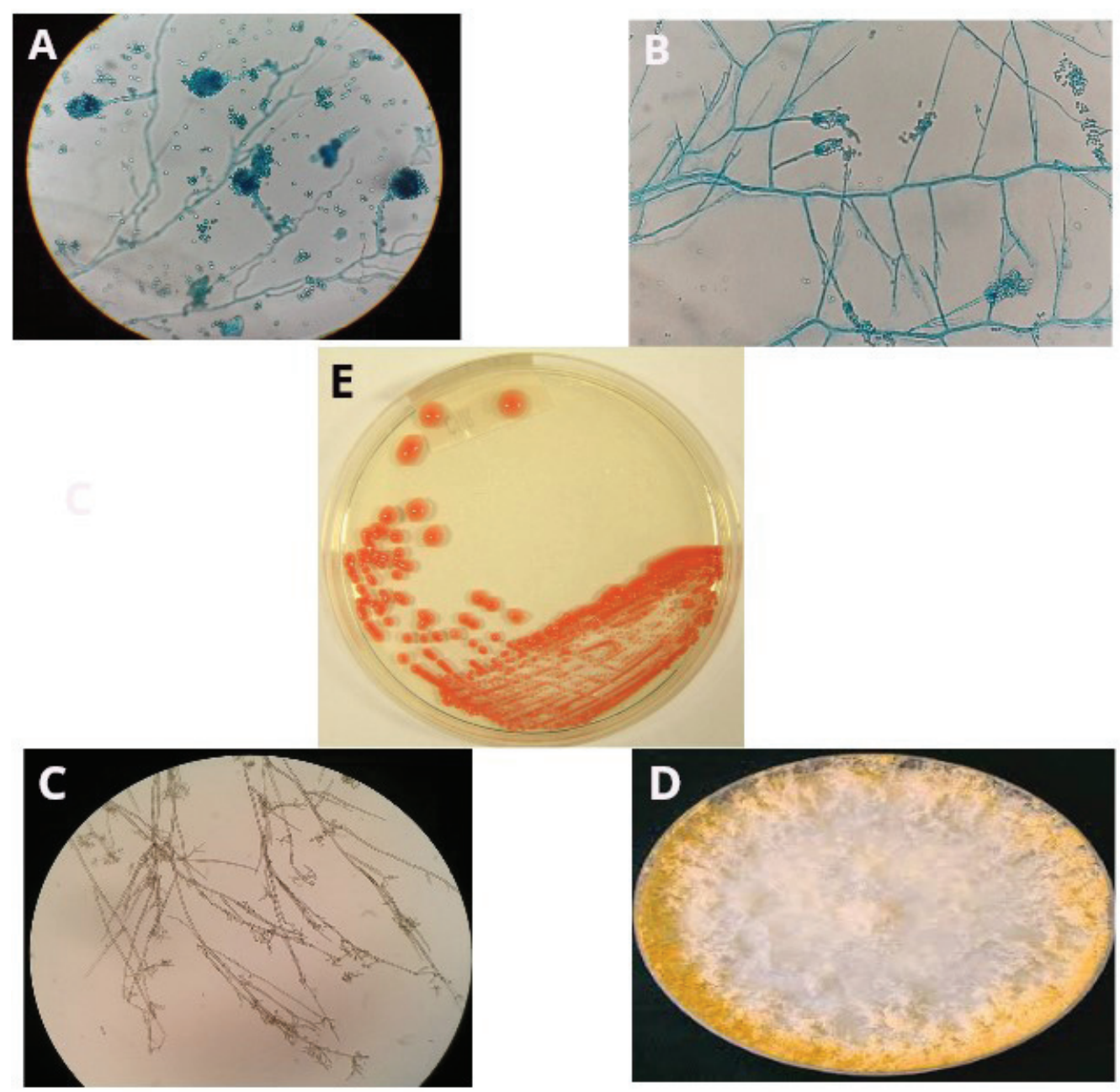

Figura 6. Géneros hallados en los laboratorios y reservas patrimoniales muestreadas: A) Aspergillus, B) Penicillium, C) Cladosporium, D) Chrysonilia, E) Rhodotorula. 
A partir de los resultados obtenidos y de la aplicación de la ecuación de Omeliansky (Análisis Ambiental, Norma Ramal de la Pesca NRP-201, 1987) se detectaron las siguientes concentraciones fúngicas: Laboratorio BIOARQ: $2325 \mathrm{UFC} / \mathrm{m}-3$, laboratorio de PCR: 1395 UFC/m-3, RPMA: 1705 UFC/m-3 y BIOARQ CIPAC: 9455 UFC/m-3.

\section{DISCUSIÓN}

Las plagas entomológicas y microbiológicas constituyen una de las mayores amenazas en museos y reservas patrimoniales (Muñoz Saba y Simmons 2005: 162). Si bien en los últimos años se ha incrementado el estudio de aspectos vinculados con la bioseguridad, principalmente orientado a cuestiones biomédicas o bioquímicas (Goldstein de Fink et al. 2008), son escasos los trabajos que aborden los riesgos de salud que enfrentan tanto los profesionales (Solís Cajas 2011, Borrego et al. 2010; Klich 2009) como las colecciones, en particular, aquellas compuestas por restos humanos (Rojo-Pérez 1998; Lopez-Martinez et al. 2007), frente a la exposición a sustancias químicas, parásitos y hongos, entre otros agentes. En general, se han realizado trabajos que han abordado el efecto de la entomofauna y hongos sobre el deterioro de cierto tipo de materiales arqueológicos o etnográficos, por ejemplo textiles (Mariani et al. 2010), herbarios o reservas patrimoniales de restos humanos momificados (Nitiu et al. 2015, Ruiz González et al. 2016, Sánchez Crispin 2009), esqueletizados (Mazza 2015) o archivos documentales y bibliotecas (Valentin 2010, Bueno et al. 2003; Moreno Batres, M.H, y J. A. Paxtor Caté. 2014). Estudios tafonómicos sobre restos arqueofaunísticos han detectado la presencia de hongos, como parte de los agentes que provocan biodeterioro en este tipo de materiales (Marozzi et al, 2015).

Este trabajo permitió detectar la presencia de hongos en todos los ambientes muestreados, en distinta frecuencia y cantidad de colonias. Se observó crecimiento fúngico en los distintos sectores obteniéndose una concentración más elevada en el interior del espacio BIOARQCIPAC con predominio de los géneros Cladosporium, Aspergillus y Penicillium, sumándose en este último caso la presencia de Chrysonilia y Rhodotorula (Figura 6). En el resto de los laboratorios analizados la concentración ambiental y la microbiota fúngica obtenidas han sido similares.

Al comparar estos valores con la escala que propone Omeliansky para evaluar el grado de contaminación del aire, se aprecia que, los valores fueron mayores a $1000 \mathrm{UFC} / \mathrm{m}-3$ por lo que el ambiente se clasifica como altamente contaminado (Análisis Ambiental, Norma Ramal de la Pesca NRP-201, 1987). Aunque no existe una norma internacional que establezca los límites para clasificar a un ambiente interior como contaminado o no, la OMS plantea que por encima de 1000 ufc.m-3 los ambientes se consideran contaminados (Nevalainen y Morawska, 2009). Esto no puede aplicarse a los resultados obtenidos del conteo de UFC de la placa expuesta en la campana de flujo laminar ya que para la misma el valor mínimo debe ser de menor a 3 UFC/placa (CECMED, REG 16-2000) por considerarse un área que debería ser estéril.

En general, los géneros detectados son frecuentemente hallados en museos, particularmente Cladosporium, Aspergillus y Penicillium, tanto en las salas de exhibición como en reservas patrimoniales (Valentin et al. 2010; Herrera et al. 2015), así como en asociación con restos humanos momificados (Lopez-Martinez 2007, Ruiz González et al. 2016). Estos géneros son agentes de degradación de diversos tipos de materiales, por su carga enzimática abundante (Robledo 1991; Ross et al. 1976). No ha sido frecuente el hallazgo de Chrysonilia y Rhodotorula, como ocurrió en el presente estudio, salvo en los estudios realizados por Herrera y colaboradores (2015) y Nitiu y colaboradores (2015), en este último caso, sobre colecciones biológicas. 
Los géneros identificados pertenecen a los filos Ascomycota y Basidiomycota, a diferencia de lo encontrado por Yang y colaboradores (2007) donde la mayoría de los hongos ambientales aislados son esporas asexuales pertenecientes al subphylum Mucormycotina.

Si bien el grado de contaminación fúngica no fue el esperado, coinciden de manera general con los resultados reportados para ambientes interiores de archivos y bibliotecas, por otros investigadores nacionales e internacionales (Borrego et al., 2010a; Rojas, 2010; Borrego \& Molina, 2014; Molina \& Borrego, 2014), lo que reafirma el criterio de que los mismos representan los contaminantes fúngicos por excelencia en los ambientes interiores destinados al almacenamiento de bienes del patrimonio histórico cultural (Rodríguez García et al. 2014)

La detección de estos microrganismos requiere una revisión de las condiciones ambientales relacionadas con la limpieza de los espacios, la ventilación, circulación del aire, entre otros.

El género más frecuente, Cladosporium, es un hongo filamentoso ambiental de distribución cosmopolita, uno de los taxa más aislado y abundante en los recuentos aerobiológicos de todo el mundo (Infante et al., 1999). Es un hongo saprófito, normalmente se encuentra colonizando las plantas o el suelo. Puede crecer en paja y madera húmeda, alimentos, combustibles fósiles, cosméticos (cremas), pinturas, plásticos, papel y tejidos (ropa, alfombras, cuero). Su temperatura óptima de crecimiento es de $18^{\circ} \mathrm{C}$ a $28^{\circ} \mathrm{C}$, la mayoría de las especies no crecen a temperaturas superiores a $35^{\circ} \mathrm{C}$. Normalmente requieren humedad relativa alta del $80 \%$ al $90 \%$. Es un agente de biodeterioro relativamente común en museos y reservas patrimoniales, generando principalmente en textiles la presencia de manchas y deterioro de los materiales (Mariani et al. 2010) y restos momificados (Ruiz González et al. 2016). Las esporas se encuentran en forma de bioaerosol en el aire, principalmente a finales de verano y principios de otoño, sobre todo en zonas templadas, siendo un contaminante habitual en los edificios o en los lugares de trabajo. Es ampliamente citado como productor de asma y rinitis, e incluso algunas de sus especies actúan como oportunistas y son capaces de intervenir en ciertos procesos micóticos pulmonares, atacar la piel, producir cromoblastomicosis y lesiones neurotrópicas. Aunque el mayor interés por estos hongos, desde el punto de vista sanitario, viene dado por la capacidad alérgena de sus conidios, que pueden alcanzar en la atmósfera, tanto en interiores como en exteriores de edificaciones, concentraciones muy altas ( Bensh et al. 2012).

El segundo género aislado mayoritariamente en nuestro estudio fue Aspergillus, uno de los principales hongos productores de micotoxinas. Las micotoxinas son metabolitos secundarios producidos y secretados por el hongo durante el proceso de degradación de la materia orgánica, como mecanismo de defensa frente a otros microorganismos. Es cosmopolita y de elevada adaptabilidad metabólica (Florian y Mannigan, 2000). Crece en cualquier tipo de sustrato, especialmente en suelos y materiales en descomposición. Es un contaminante habitual de los conductos de climatización-ventilación. Es termotolerante, puede vivir entre $\operatorname{los} 12^{\circ} \mathrm{C}$ y $\operatorname{los} 57^{\circ} \mathrm{C}$. La transmisión se produce principalmente por medio de las esporas o conidios que se encuentran presentes en el ambiente de trabajo en forma de bioaerosoles y penetran en el organismo por vía respiratoria. También es posible la transmisión por contaminación de heridas o mucosas y la aparición de efectos tóxicos por ingestión de alimentos contaminados. No se produce transmisión de persona a persona. El efecto que tiene sobre materiales arqueológicos, principalmente textiles, es el de generar manchas y crecimiento micelar sobre los mismos, así como generar ácidos y enzimas que provocan biodeterioro a largo plazo (Mariani et al. 2010). 
Otro género detectado fue Penicillium; son hongos filamentosos que se encuentran en suelo, vegetación y en aire. Incluye varias especies, dentro de las más comunes encontramos $P$. chrysogenum, P. claviforme, P.marneffei, P. purpurogenum, entre otras. Al igual que Aspergillus, tiene distribución cosmopolita (Florian y Manning 2000). La mayoría de sus especies son consideradas contaminantes (excepto P. marneffei), pero se han encontrado como agentes causales de infección en pacientes inmunocomprometidos, así como de infecciones superficiales, causando otomicosis y queratitis. En el caso de las colecciones arqueológicas, se ha reportado su presencia asociada a textiles, en los cuales provoca manchas y secreción de enzimas celulolíticas y lignolíticas que dañan los materiales (Mariani et al. 2010).

Con respecto a Chrysonilia es un hongo de rápido crecimiento, que presenta un aspecto medianamente algodonoso, con masas de color rosa a anaranjado. Al microscopio se observa hifas septadas, con ramificaciones laterales que formarán cadenas de conidias. Es considerado un moho aeroalérgeno y puede inducir asma ocupacional en personal expuesto (Francuz et al. 2010).

En cuanto a Rhodotorula, son levaduras saprofitas ubicuas que pueden recuperarse de muchas fuentes ambientales. Es una levadura ambiental común que se encuentra en el aire, el suelo, los lagos, el agua del océano, la leche y el zumo de frutas. Las especies de Rhodotorula, pertenecen al filo Basidiomycota, colonizan plantas, humanos y otros mamíferos. El género Rhodotorula incluye ocho especies, de las cuales se sabe que $R$. mucilagino$s a, R$. glutinis y $R$. minuta causan enfermedades en humanos (Wirth y Goldani, 2012). Rhodotorula produce colonias rosadas a rojas y blastoconidias que son unicelulares y carecen de pseudohifas (Larone, 1995). Rhodotorula spp, es una levadura que coloniza a los seres humanos, puede ser parte de la microbiota normal de piel y mucosas y producir infecciones a partir de la formación de biopelicu- las en elementos biomédicos como catéteres. Rara vez produce cuadros pulmonares, infección de vías urinarias, meningitis y fungemias en pacientes inmunocompetentes, pero es un patógeno de alto riesgo en pacientes inmunocomprometidos.

Con respecto a la metodología de trabajo empleada, presenta algunas limitaciones. El muestreo por gravedad, es un método no cualitativo en el que las placas con medio de cultivo son expuestas al ambiente y los organismos son colectados principalmente por precipitación. La recolección de microorganismos por este método está afectada por el tamaño y la forma de las partículas y por el movimiento del aire circulante. Como resultado de ello, las partículas grandes tienen mayor probabilidad de ser depositadas en la superficie de recolección. Esto puede llevar a la tergiversación de la prevalencia de microrganismos ambientales y a la exclusión de las partículas pequeñas del muestreo. Tampoco, la concentración de hongos ambientales puede ser determinada por este tipo de muestreo porque el volumen del aire considerado no es conocido (Buttner et al. 1997).

El método de sedimentación ha sido estandarizado desde 2004 para la cuantificación de la microbiota en ambientes interiores de museos, archivos y bibliotecas por Borrego y colaboradores (Borrego y Perdomo, 2012). El estudio se realizó mediante esta última metodología, ampliamente reportada en estudios aerobiológicos en el mundo entero (Abdel Hameed et al. 2012; Mawla, 2012). En los últimos años se ha validado el empleo del método de viables por sedimentación para la realización de este tipo de estudios, reportando concentraciones fúngicas generalmente en el rango de ambientes de poco a no contaminados.

\section{CONCLUSIONES}

Consideramos que la realización de este tipo de estudios que evalúan la calidad del aire, y por lo tanto la existencia de agentes que pueden 
causar biodeterioro a colecciones y a los agentes que trabajan con ellas, son de fundamental importancia. Permiten caracterizar los agentes presentes y así, desarrollar un plan de acción que permita disminuir los riesgos que conlleva su presencia, tanto para las colecciones como para la salud humana. En particular, la presencia de hongos provoca en las estructuras edilicias tres efectos principales: daños en la estructura del edificio, malos olores y efectos adversos en la salud de personas sensibles. Dado que ambientes con humedad relativa que supere el $65 \%$, y una temperatura mayor a $18^{\circ} \mathrm{C}$ generan condiciones propicias para la reproducción de los hongos (Valentin et al. 2010: 61), es recomendable implementar cambios que contemplen no solo la inhibición en el crecimiento de estos organismos, sino también modificaciones en las características de los ambientes físicos (Giudice, 2003), por ejemplo, mejorando la ventilación o disminuyendo la humedad relativa (Aranda et. al. 2014).

Los análisis rutinarios, teniendo en cuenta el recuento de hongos y bacterias mesófilas aerobias, así como la búsqueda de bioindicadores potenciales como Cladosporium, Penicillium y Aspergillus en el interior de edificaciones públicas y no industrializadas, en diversas regiones geográficas y climáticas, podrían contribuir a la estandarización de especificaciones de la calidad del aire interior, especialmente en países en vía de desarrollo.

Si bien en este estudio se detectó la presencia de hongos que se encuentran normalmente en el ambiente, el género al que pertenezcan o su alta concentración pueden provocar distintos tipos de patologías alérgicas. Si bien puede que inhalemos conidias de estos mohos en cualquier momento de nuestras vidas, sólo si encuentran condiciones favorables, como una gran disminución de las defensas de nuestro organismo, serían capaces de producir enfermedad en el hombre (López Martínez et al. 2004).

Proponemos las siguientes medidas de prevención y control para espacios de trabajo simila- res a los presentados por Sanchez-Paya (2001), y la Sociedad Española de Medicina Preventiva, Salud Pública e Higiene (SEMPSPH 2000):

- Limpiar las mesadas de trabajo con hipoclori to $1 \%$, seguido de alcohol $70 \%$. La misma deberá realizarse diariamente, al comenzar la actividad y al terminar la jornada.

- Irradiar las mesadas de trabajo con luces UV, por un mínimo de 15 minutos, antes de comenzar el trabajo y después de finalizado. Estas dañan el ADN de los organismos presentes, incluidos los hongos, impidiendo que se reproduzcan y, consecuentemente, disminuyendo su presencia.

- Evitar las corrientes de aire. Mantener puertas y ventanas cerradas en los lugares de trabajo, especialmente en aquellos donde se realicen procedimientos de laboratorio.

- Disponer de ventilación adecuada en los lugares de trabajo, evitar la humedad relativa alta y las condensaciones.

- Evitar plantas de interior decorativas.

- Implantar un cronograma semanal de limpieza y mantenimiento de locales, instalaciones y equipos, especialmente en el sistema de climatización-ventilación del edificio.

- Eliminar diariamente los residuos que se generen en los espacios de trabajo, principalmente si consisten en materiales orgánicos o húmedos, para prevenir el enmohecimiento. Nunca conservar alimentos en los espacios de trabajo. Evitar procesos pulvígenos o que generen bioaerosoles. Si no es posible el aislamiento de dichos procesos, disponer de un sistema de extracción localizada.

- Utilizar guantes descartables y derrocharlos inmediatamente después de su uso, impidiendo el traslado hacia otros espacios de trabajo/laboratorios, lo cual puede acarrear esporas de hongos.

Si bien en este estudio se trabajó con un muestreo no volumétrico, consideramos que permitió generar información útil sobre la presencia de hongos ambientales en el área testeada, sabiendo que su presencia es incuestionable y difícil de erradicar. Es recomendable realizar frecuente- 
mente controles como los aquí presentados, para evaluar la presencia de hongos ambientales y, después de tomar medidas correspondientes, evaluar nuevamente si estos disminuyeron. Es importante poner en conocimiento a todo el personal de los resultados del trabajo, a los fines de implementar nuevas medidas para mejorar la calidad del ambiente de trabajo.

\section{AGRADECIMIENTOS}

A las instituciones que permitieron la realización de este trabajo. Esta investigación forma parte del proyecto "Poblaciones originarias del centro de Argentina: aportes para su estudio desde la Bioarqueología, la Arqueogenética y la Genética del Paisaje" (PICT 2015-3155).

\section{REFERENCIAS}

Abdel Hameed, A.A., Ayesh, A.M., Razik Mohamed, M.A., y Abdel Mawla, H.F. Fungi and some mycotoxins producing species in the air of soybean and cotton mills: a case study. 2012. Atmospheric Pollution Research, 3: 126-131.

Aira, M., E. Piontelli Laforet, M. Jato Rodriguez y M. Toro Santa María. Concentración atmosférica invernal de propágulos fúngicos en un mercado interior de abastos en Valparaíso. 2003. Boletín Micológico 18:29-37.

Albright, D. Human health effects of airborne mycotoxins exposure in fungi-contaminated indoor environment. 2001. Professional Safety, 46(11), 26-28.

Análisis Ambiental. 1987. Método de Omeliansky. Análisis higiénico sanitario y ambiental. Métodos de ensayos microbiológicos. 7 pps. Norma Ramal de la Pesca NRP-201. Ciudad de La Habana. Ministerio de la Industria Pesquera.

Aranda, C., L. Luna, N. Costanzo, V. Contissa, N. Gámez, P. Godoy, K. Zuccala. Conservación e investigación en el área de Antropología Biológica del Museo Etnográfico J. B. Ambrosetti (Facultad de Filosofía y Letras, Universidad de Buenos Aires, Argentina). 2014. Antropologia Portuguesa. Vol. 30/31: 11-28.

Awad, AH y Mawla, AH. Sedimentation with tneOmeliansky formula as an accepted technique for quantifying airborne fungi. 2012. Pol. J. Environ. Study; 21 (6): 1539-1541.
Barnet, H.L. y Hunter, B.B. Illustrated Genera of Imperfect Fungi. 1997. New York, USA: MacMillan Publisher Co.

Borrego S., Guiamet P., Gómez de Saravia S., Batistini P., García M., Lavin P. y Perdomo I. The quality air at archives and the biodeterioration of photographs. 2010. International Biodeterioration and Biodegradation 64:139-145.

Borrego, S.; Lavin, P., Perdomo, I.; Gómez de Saravia, S.; y Guiamet, P. Determination of Indoor Air Quality in Archives and Biodeterioration of the Documentary Heritage. 2012. International Scholarly Research Network, ISRN Microbiology, doi:10.5402/2012/680598

Bueno, D., Silva, J.O. y G. Oliver. Hongos ambientales en una biblioteca: un año de estudio. 2003. Anales de documentación, 6: 27-34

Buttner MP, Willeke K, Grinshpun SA. Sampling and analysis of airborne microorganisms. 1997. En: Manual of Environmental Microbiology. USA: ASM Press; pp. 629-640

Daza Pérez, M.A., Martinez Benavidez, D. X y Caro Hernández, P.A. Contaminación microbiológica del aire al interior y el síndrome del edificio enfermo. Universidad Libre Seccional Barranqui1las.2015. Biociencias. 10 (2):37-50.

Florian, M. y Manning, L. SEM analysis of irregular fungal fox spots in an 1854 book: population 
dynamics and species identification. 2000. International Biodeterioration and Biodegradation, 46, 205-220.

Francuz, B., Yera, H., Geraut, L., Bensefa-Colas, L., Nghiem, Z. H. y Choudat, D. Occupational Asthma Induced by Chrysonilia sitophila in a Worker Exposed to Coffee Grounds. 2010. Clinical and Vaccine Inmunology. 17(10): 1645-1646.

García, J. C. R. Microbiología aplicada: una herramienta para la conservación del Patrimonio Cultural. 2016. Conservar Património, 1(1), 23-36.

Goldstein de Fink S; Miguel S; Sanjuan C; Metallo O y A. Tezon. Desarrollo de normativa para Bioseguridad en Argentina. Latino América. 2008. Laboratory Biosafety and Biosecurity Conference. Laboratorios Nacionales Sandia, EEUU.

Guerrero, T., D. Ruiz Sánchez, J. Martínez Chacón, 2003. Aislamiento de hongos en instalaciones deportivas de la UNAM. Revista de la Facultad de Medicina UNAM 46(3): 93-96.

Giúdice, C. 2003. Patrimonio cultural: limpieza, consolidación y pretratamiento con biocidas. I Jornadas Iberoamericanas sobre Biodeterioro del Patrimonio Cultural Iberoamericano. Prevención Restauración y Preservación. CYTED, Colombia.

Grupo de trabajo de la Sociedad Española de Medicina Preventiva, Salud Pública e Higiene y el INSALUD. Recomendaciones para la Verificación de la Bioseguridad Ambiental (BSA) respecto a hongos oportunistas. Madrid, 2000. Disponible en https://www.sempsph.com/ es/documentos-sempsph/higiene-hospitalaria/ article/117090-recomendaciones-para-la-verificacion-de-la-bioseguridad-ambiental-bsa-respectoa-hongos-oportunistas).

Grupo colaborador de GEGMIC. Recomendaciones generales para el control de calidad interno en Micología Clínica: CCI-SEIMC-08. Versión 1. 16/05/2014. Disponible en https://seimc.org/contenidos/gruposdeestudio/gegmic/dcientificos/documentos/gegmic_dyc1_2004.pdf

Herrera, K, Cóbar, O, Barrios, R, Pierola, K, Chamalé, W. Rosales, C, Quan, J, Moreno, M, Paxtor, J y Maas, J. Evaluación de la contaminación del aire por hongos microscópicos en dos colecciones biológicas y dos museos de la ciudad de Guatemala. 2015. Revista Científica, 25 (2):43-58.

Infante, F., Castro, A., Domínguez, E., Gúadia, A., Méndez, J., Sabariego, S y Vega, A. A comparative study of the incidence of Cladosporium conidia in the atmosphere of five Spanish cities. 1999. Polen, 10, 15-23.

Klich M.A. Health effects of Aspergillus in food and air, Toxicology and Industrial 2009. Health 25 (9-10):657-667.

Larone DH. Hongos médicamente importante: una guía para la identificación. 1995. Tercera edicion Washington, DC, EE. UU .: Sociedad Americana de Microbiología.

López-Martínez, R., F. Hernández-Hernández, B. Millán-Chiu, P. Manzano-Gayosso, y L. J. Méndez-Tovar. Efectividad del imazalil en el control del deterioro por hongos de momias del museo de El Carmen, Ciudad de México. 2007. Rev Iberoam Micol, 24: 283-288.

Mariani, R., A. Igareta, G. Varela, S. Gómez Saravia, P. Guiamet. Entomofauna presente en textiles de colecciones arqueológicas y otros factores de riesgo de biodeterioro. 2010. Actas del $1^{\circ}$ Congreso Latinoamericano y II Congreso Nacional de Museos Universitarios, Universidad Nacional de La Plata.

Marozzi, A., M. Mondini y E. Pintar. Tafonomía de vertebrados holocénicos del sitio arqueológico cueva salamanca 1 en la puna salada argentina. 
2015. Comechingonia, Revista de Arqueología, 19 (1): 11-36.

Mazza, B. Colecciones antiguas, datos nuevos: Primeros resultados del análisis de las colecciones bioarqueológicas del Humedal del Paraná Inferior. 2015. Revista del Museo de Antropología, 8(1): $133-146$

Molina V. y S. Borrego A. Análisis de la micobiota existente en el ambiente interior de la mapoteca del Archivo Nacional de la República de Cuba. 2014. Bol. Micol. 29(1): 2-17

Molina V. y S. Borrego A. Aerobiología y biodeterioro del género Aspergillus link en depósitos de tres instituciones patrimoniales cubanas. 2016. Bol. Micol. 31(1): 2 - 18

Moreno Batres, M.H, y J. A. Paxtor Caté. Determinación de la contaminación del aire por hongos microscópicos en dos museos de la ciudad de Guatemala. 2014. Tesis de Licenciatura. Universidad de San Carlos de Guatemala Facultad de Ciencias Químicas y Farmacia, Escuela de Química Biológica. Ms. Inédito.

Muñoz Saba, Y. y J. Simmons. Manejo Integrado de plagas. En: Cuidado, Manejo y Conservación de Colecciones Biológicas. 2005. Universidad Nacional de Colombia, Instituto de Ciencias Naturales, Bogotá, Colombia, pp. 162-188.

Nevalainen, A. y Morawaska, L. Biological Agents in Indoor Environments. Assessment of Health Risks. 2009. Work conducted by a WHO Expert Group between 2000-2003. Disponibleen http:// www.ilaqh.qut.edu.au/Misc/BIOLOGICAL_AGENTS_2009.pdf

Nitiu, DS.;Mallo, AC.; Lorena A. Eliades; San Martin, C.; M. C.N. Saparrat. Estrategias metodológicas para el monitoreo aeromicológico en el Museo de La Plata. 2015. Actas del IV Congreso
Iberoamericano y XII Jornada de Técnicas de Reparación y Conservación del Patrimonio, Laboratorio de Entrenamiento Multidisciplinario para la Investigación Tecnológica (LEMIT), La Plata, pp. 382-388.

Robledo M.S. Caracterización taxonómica, distribución y algunos aspectos fisiológicos de Aspergillus spp. que deterioran documentos en el Archivo General de la Nación. 1991. Tesis de Maestría en Ciencias Biológicas. México, UNAM, 1991.

Rojo-Pérez F. Riesgos ocupacionales por manejo de restos momificados. 1998. Tesis de Licenciatura en Antropología Física. Escuela Nacional del Antropología e Historia, México, UNAM, 1998.

Ross RT, Hollis CG. Microbiological deterioration of pulpwood, paper, and paint. 1976. New York, Mc Graw Hill, 309-354.

Ruiz González, J., Bazán Mora, E., Barrera Moreno, K y López Martínez, R. Estudio micológico para la conservación de las momias de Tlayacapan, Morelos. 2016. Estudios de Antropología Biológica, 18 (2): 55-67.

Sáchis, J. Los nueve parámetros más críticos en el muestreo microbiológico del aire. 2002. Rev. Tecn. Lab, 276, 858-862.

Sánchez Crispín, M. Identificación de bacterias y hongos asociados a las momias de Caltimacán, Tasquillo, Hidalgo. 2009. Tesis de licenciatura, ENAH, México, D.F.

Sanchez- Payá, J. Control de la Bioseguridad ambiental. 2001. Rev. Iberoamericana de Micol, 19: 1-10.

Sehulster LM, Chinn RYW, Arduino MJ, Carpenter J, Donlan R, Ashford D, Besser R, Fields B, McNeil MM, Whitney C, Wong S, Juranek D. y Cleveland J. Guidelines for environmental infection control in health-care facilities. 2003. Recom- 
mendations from CDC and the Healthcare Infection Control Practices Advisory Committee (HICPAC). Chicago IL; American Society for Healthcare Engineering/American Hospital Association. Disponible en https://www.cdc.gov/infectioncontrol/pdf/ guidelines/environmental-guidelines-P.pdf

Solis Cajas, E. Estudio micológico del aire en áreas ocupacionales y exteriores del laboratorio de investigacion en productos, ciudad universitaria. 2011. Tesis de Licenciatura, Universidad de San Carlos de Guatemala. Ms Inédito.

Sterfinger, K. Fungi: their role in deterioration of cultural heritage. 2010. Fung. Biol. Rev.24: 47-55.
Valentin, N. Microorganism in museum collections. 2010. Coalition, $19: 2-5$.

Valentin, N., C. Muro y J. Montero. Métodos y Técnicas para Evaluar la Calidad del Aire en $\mathrm{Mu}-$ seo: Museo Nacional Centro de Arte Reina Sofía". 2010. Ed. CARS - IIC Grupo Español: 63-81.

Wirth, F. y L.Z. Goldani. Epidemiology of Rhodotorula: an emerging pathogen. 2012. InterdiscipPerspectInfectDis. 2012:1-7.

Yang CS, Johanning E. Airborne fungi and mycotoxins. 1997. En Manual of Environmental Microbiology. USA:ASM Press, pp. 651-660. 